\title{
Measurements of liver stiffness in patients with left ventricular assist devices
}

\author{
Teruhiko Imamura' ${ }^{1}$
}

Received: 6 June 2019 / Accepted: 12 July 2019 / Published online: 19 July 2019

๑) Springer Japan KK, part of Springer Nature 2019

Keywords Heart failure $\cdot$ Hemodynamics $\cdot$ Right ventricular failure

To the editor,

I have read with great interest a manuscript of Omote and colleagues, demonstrating that increased liver stiffness, which was non-invasively assessed by virtual touch quantification on admission, was an independent determinant of all-cause mortality and worsening heart failure in patients hospitalized due to acute decompensated heart failure [1]. Their study was based on the previous finding that liver stiffness was associated with central venous pressure [2]. Thus far, increasing numbers of patients with advanced heart failure receive left ventricular assist device (LVAD) therapy. Although nobody has reported, I believe that the methodology that they used might also be adopted for the follow-up of LVAD patients.

Our team recently demonstrated that hemodynamics, particularly elevated central venous pressure, which was invasively measured by right heart catheterization, was associated with various comorbidities including hemocompatibility-related adverse events such as gastrointestinal bleeding during LVAD supports [3]. Furthermore, we demonstrated that aggressive hemodynamic optimization by adjusting LVAD speed and medications was associated with improvement in clinical outcomes [4]. However, repeated right heart catheterizations have risks of bleeding and infection, particularly under LVAD support with anti-coagulated condition. It might be a future concern to investigate whether liver stiffness-guided hemodynamic optimization would improve clinical outcomes during LVAD support.

Teruhiko Imamura

te.imamu@gmail.com

1 Division of Cardiology, Department of Medicine, University of Chicago Medical Center, 5841 S Maryland Avenue,

Chicago, IL 60637, USA

\section{Compliance with ethical standards}

Conflict of interest The author declares that have no competing interest.

\section{References}

1. Omote K, Nagai T, Asakawa N, Kamiya K, Tokuda Y, Aikawa T, Fukushima A, Noguchi K, Kato Y, Komoriyama H, Nishida M, Kudo Y, Iwano H, Yokota T, Anzai T (2019) Impact of admission liver stiffness on long-term clinical outcomes in patients with acute decompensated heart failure. Heart Vessels 34:984-991

2. Taniguchi T, Sakata Y, Ohtani T, Mizote I, Takeda Y, Asano Y, Masuda M, Minamiguchi H, Kanzaki M, Ichibori Y, Nishi H, Toda K, Sawa Y, Komuro I (2014) Usefulness of transient elastography for noninvasive and reliable estimation of right-sided filling pressure in heart failure. Am J Cardiol 113:552-558

3. Imamura T, Nguyen A, Kim G, Raikhelkar J, Sarswat N, Kalantari S, Smith B, Juricek C, Rodgers D, Ota T, Song T, Jeevanandam V, Sayer G, Uriel N (2019) Optimal haemodynamics during left ventricular assist device support are associated with reduced haemocompatibility-related adverse events. Eur J Heart Fail 21:655-662

4. Uriel N, Burkhoff D, Rich JD, Drakos SG, Teuteberg JJ, Imamura T, Rodgers D, Raikhelkar J, Vorovich EE, Selzman $\mathrm{CH}$, Kim G, Sayer G (2019) Impact of hemodynamic ramp test-guided HVAD speed and medication adjustments on clinical outcomes. Circ Heart Fail 12:e006067

Publisher's Note Springer Nature remains neutral with regard to jurisdictional claims in published maps and institutional affiliations. 